\title{
DIREITO, TRANSNACIONALIDADE E SUSTENTABILIDADE EMPÁTICA
}

\author{
RIGHT, TRANSNATIONALITY AND EMPATHIC \\ SUSTAINABILITY
}

\author{
Marcelo Buzaglo Dantas ${ }^{1}$ \\ Maurizio Oliviero ${ }^{2}$ \\ Paulo Márcio Cruz ${ }^{1}$
}

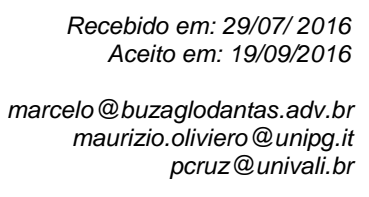
pcruz@univali.br

Resumo: O presente artigo científico possui como objetivo discutir alguns aspectos dos postulados da transnacionalidade jurídica e de suas teorias e práticas avaliadas e descritas em suas trajetórias evolutivas, seus paradigmas estruturais e relações com a sociedade e a história. E também a partir do espargimento da sustentabilidade como possível novo paradigma das ciências no mundo globalizado e suas possíveis repercussões no direito e na ciência jurídica. Na metodologia foi utilizado o método indutivo na fase de investigação; na fase de tratamento de dados o método cartesiano e no relatório da pesquisa foi empregada a base indutiva. Foram ainda acionadas as técnicas do referente, da categoria, dos conceitos operacionais, da pesquisa bibliográfica e do fichamento.

Palavras-chave: Direito Ambiental. Transnacionalidade. Sustentabilidade.

\begin{abstract}
This scientific paper aims to discuss some aspects of the postulates of legal transnationality and its theories and its practices evaluated and described in their evolutionary trajectories, their structural paradigms and relations with society and history. And also from the sprinkling of sustainability as a possible new paradigm of science in the globalized world and its possible repercussions on law and legal science. In the methodology was used the inductive method in the research phase; in the data processing phase the Cartesian method and in the research report was employed the inductive base. They were also triggered the techniques of reference, category, operational concepts, bibliographic research and book report.
\end{abstract}

Keywords: Environmental Law. Transnationality. Sustainability.

\section{INTRODUÇÃO}

O presente trabalho científico possui como escopo principal traçar alguns dos entrelaces ideológicos entre o Direito, a Transnacionalidade e a Sustentabilidade Empática, traduzindo-se nesse sentido o tema proposto.

A escolha do tema foi construída a partir dos debates e seminários realizados por seus autores. O Prof. Paulo Márcio Cruz durante seu último Estágio Sênior com bolsa CAPES nas universidades de Alicante, na Espanha, e de Perugia, na Itália, nos anos de 2014 e 2015. O Prof. Maurizio Oliviero durante sua estada na UNIVALI, de 2012 a 2015 como Professor Visitante do Exterior - PVE com bolsa CAPES. E o Prof. Dr. Marcelo Dantas no desenvolvimento das atividades de pós-doutorado, também com bolsa CAPES, a partir de 2014 no Programa de Pós-Graduação Stricto Sensu em Ciência Jurídica - PPCJ/UNIVALI, em seus cursos de Mestrado e Doutorado.

Nesse diapasão, seu objetivo foi o de discutir alguns aspectos dos postulados da transnacionalidade jurídica e de suas teorias e práticas avaliadas e descritas em suas trajetórias

\footnotetext{
${ }^{1}$ Universidade do Vale do Itajaí - UNIVALI - Itajaí - Santa Catarina - Brasil

${ }^{2}$ Universidade de Perugia - Itália.
} 
evolutivas, seus paradigmas estruturais e relações com a sociedade e a história. E também a partir do espargimento da sustentabilidade como possível novo paradigma das ciências no mundo globalizado e suas possíveis repercussões no direito e na ciência jurídica.

O estudo traz como base teórica principal dois autores que respeitamos muitíssimo: Gabriel Real Ferrer e Jeremy Rifkin. Gabriel Real por ser, atualmente, um autor fundamental quando se trata de sustentabilidade. Rifkin por sua oportuna proposição do surgimento de uma "civilização empática".

Na metodologia foi utilizado o método indutivo na fase de investigação; na fase de tratamento de dados o método cartesiano e no relatório da pesquisa foi empregada a base indutiva. Foram ainda acionadas as técnicas do referente, da categoria, dos conceitos operacionais, da pesquisa bibliográfica e do fichamento.

\section{O DIREITO, A TRANSNACIONALIDADE E A SUSTENTABILIDADE EMPÁTICA}

Desde a crise do petróleo, na década de 70, passando pela derrocada do socialismo soviético no final da década de 80 do Século passado que o mundo, em maior ou menor grau, percebe aumentar essa sensação de esgotamento das bases modernas que levaram a civilização ocidental a paradoxos impressionantes.

Durante a Guerra Fria o pesadelo era a Terceira Guerra Mundial, uma guerra nuclear. Bombas atômicas começariam a ser lançadas contra as principais capitais do mundo e a vida estaria seriamente ameaçada na Terra. Depois a humanidade - a parte dela que consegue discernir alguma coisa - deu-se conta que a corrida armamentista era, na verdade, uma forma de "capitalismo bélico" e que raras foram as vezes que os líderes pensaram seriamente em abrir aquelas maletas com os controles sobre o lançamento dos mísseis com ogivas nucleares.

Nessa época de Guerra Fria algumas coisas eram muito interessantes do ponto de vista acadêmico-científico. Uma delas é - ou era - uma dessas alegorias capitalistas chamada de "dívida externa". Durante a ditadura de 64 a 85 e mesmo após os governos civis, volta e meia desembarcava em Brasília alguém do Fundo Monetário Internacional - FMI. As pessoas não sabiam se ficavam preocupadas com a possibilidade das bombas atômicas - o que foi se dissolvendo a partir do colapso soviético de 89 - ou com o tal de FMI.

O fato é que o capitalismo passou a reinar absoluto com o fim da União Soviética e com a China se esbaldando com seu sistema "comunismo para dentro (cada vez menos) e capitalismo para fora (cada vez mais)". Um processo de "Mais do Mesmo", como dizem os que gostam de frases de efeito.

Mas o fato irrefutável é que o mundo, nesses últimos 50 anos mudou muito. As pessoas mudaram. As comunicações mudaram. A cultura mudou. A geopolítica mudou. A Primavera Árabe aconteceu e os problemas dos países árabes pioraram. Os BRICS (Brasil, Rússia, Índia, China e África do Sul) passaram a ser pretensos membros de mais um polo da economia mundial. Com a crise político-econômica atual já não se sabe mais a validade dessa perspectiva. 
A sofisticação das comunicações e as redes sociais se encarregaram de criar um intenso processo global de aumento - assimétrico é verdade - da complexidade nas diversas sociedades nacionais e nacionais estatais no planeta.

Todas as áreas do conhecimento foram e estão sendo atingidas em cheio por isso que podemos chamar de fim da segunda modernidade. Ou, talvez seja mais adequado, da saturação seletiva de alguns corolários modernos.

Mas isso tudo que aconteceu nas últimas cinco décadas acabou por dar início ao que Rifkyn chama de construção de uma "civilização empática" (RIFKIN, 2010). Há uma espécie de "Blade Runner" no sentido de se buscar na sociedade em rede o direito de não saber qual o próximo nível obrigatório de apreensão tecnológica, nano tecnológica, antropotecnológica. Pedimos desculpas por um neologismo aqui e outro ali.

Encontramos-nos num momento decisivo da história, porque o caminho para uma consciência global compartilhada está sendo trilhado de maneira muito rápida e acompanhado por intervenções humanas na natureza cada vez mais intensas. É o que Rifkin chama de "colapso entrópico"3. O aumento das pautas globais comuns é algo que impressiona, mas o aumento das agressões humanas ao ambiente não fica atrás.

E esse provavelmente é um dos principais critérios para que um novo valor com pretensão de se tornar um paradigma de todas as ciências possa se consolidar. Sem esse elemento "conectivo" não há como se formar concepções teóricas majoritárias a ponto de serem capazes de criar uma ampla base de apoio com crédito suficiente, o que é fundamental para que se estabeleça em definitivo um novo paradigma.

Sendo verdade que a natureza humana ${ }^{4}$ é materialista, egoísta, utilitária e se centra na busca pelo prazer, haverá poucas esperanças de se resolver o paradoxo antropo-empático, como sugere Rifkin. Mas, se em um nível mais básico a natureza humana está orientada ao afeto, ao companheirismo, à sociabilidade e à extensão das empatias humanas, pelo menos existe a possibilidade de que possamos superar esse paradoxo e chegar a uma solução que nos permita restabelecer um equilíbrio sustentável com a biosfera.

Essa talvez seja um dos pontos mais importantes para encontrarmos o caminho para a consolidação da sustentabilidade como novo paradigma a matizar todo o conhecimento humano.

Rifkin aponta que, pouco a pouco, foi ganhando força uma imagem nova e radical da natureza humana que possui implicações revolucionárias para nossa forma de entender e organizar as relações sociais e ambientais nos séculos que virão. É possível assistir o surgimento de uma empatia que se globaliza dia a dia e que esparge pelo planeta o Homo Empáthicus, como escreve Rifkin (2010). Seremos humanos com sentimentos comuns de pertencimento a uma comunidade global conectada e interativa.

\footnotetext{
${ }^{3}$ Para uma série de exemplos de tragédias ambientais causadas pelo homem, v. DIAMOND, 2010. Sobre casos ambientais célebres levados ao Judiciário em 8 diferentes países, v. HOUCK, 2010.

${ }^{4}$ Sobre essa perspectiva da atual defesa dos direitos humanos, que reavivou a discussão acerca da fundamentação do direito ver Souza; Pinheiro (2016)
}

Revista do Direito [ISSN 1982-9957]. Santa Cruz do Sul, v. 2, n. 49, p. 29-45, maio/ago. 2016. https://online.unisc.br/seer/index.php/direito/index 
Nós que cuidamos do Direito, ou da Ciência Jurídica, não podemos e não devemos desconsiderar essa realidade. Nem sabemos mais se podemos chamar o sistema normativo do Estado Constitucional Moderno de "direito".

Podemos nos valer de um dos nossos mais brilhantes docentes do PPCJ/UNIVALI, doutorado pela UNIVALI e pela Universidade de Perugia, o professor e magistrado Orlando Zanon, para começarmos a poder discutir de maneira minimamente conveniente a crise na teoria do Direito. Ou na teoria jurídica. O processo de revolução científica, nos moldes propostos por Kuhn (2000), caracterizado pela substituição gradual dos principais postulados do modelo teórico do Jus positivismo já não mais oferece respostas adequadas aos problemas sociais. Principalmente em decorrência do aumento da complexidade nas relações intersubjetivas, da ampliação da interdisciplinaridade e da progressão da reflexividade transnacional, diz Zanon (2015). E tem razão!

Mas é, além disso, que queremos ir: nosso objetivo é discutir o processo de transnacionalidade político-jurídica e a formação de elementos de transnacionalização do direito.

A mudança progressiva do paradigma moderno para o novo paradigma faz com que cada vez mais pesquisadores de todas as áreas do conhecimento convirjam para a sustentabilidade a uma velocidade espantosa. E isso não é oportunismo científico! É estar se dando conta que as bases do paradigma moderno estão em franco processo de esfacelamento. O que se faz agora é também acelerar o debate sobre a formação da base conceitual e de caracterização para a categoria Direito Transnacional $^{5}$, que atualmente ainda se apresenta de maneira difusa e com algumas categorias construtivas, como o é o Transconstitucionalismo e o Transjudicialismo.

Importante assinalar que para que se abra o debate sobre essas categorias, é fundamental considerar que a liberalização do mercado mundial, como escreve Habermas (2001) ${ }^{6}$, progrediu muito. A mobilidade do capital acelerou e o sistema industrial foi modificado, saindo da produção de massa e passando a se adequar às necessidades da "flexibilidade pós-fordista". Com os mercados cada vez mais globalizados, o equilíbrio alterou-se prejudicando claramente a autonomia e a capacidade de ação político-econômica dos estados constitucionais modernos. (HABERMAS, 2001, p. 99).

É imperioso reconhecer o surgimento de fenômenos que alteram a compreensão tradicional e corrente das categorias modernas do Direito.

Essas alterações permitem projetar mudanças que, embora careçam de sustentação empírica, deflue de um consenso mínimo axiológico gerador de novos modelos.

Normalmente, nos debates dos quais temos participado, pesquisadores mais "conservadores" (talvez até não seja o adjetivo mais adequado) continuam dando voltas e tentando analisar a crise do direito moderno a partir de releituras de filósofos tradicionais, de Kant a Habermas. Se bem que esse último já tem nos trazido muitas reflexões sobre o mundo pós-moderno. O filósofo alemão começa a

\footnotetext{
${ }^{5}$ Trata-se também de um esforço teórico desenvolvido na construção das bases epistemológicas que estão sendo adotadas no Curso de Doutorado em Ciência Jurídica da Univali (www.univali.br/ppcj), tanto em sua área de concentração, denominada CONSTITUCIONALISMO, TRANSNACIONALIDADE E PRODUÇÃO DO DIREITO, quanto em uma de suas linhas de pesquisa intitulada ESTADO E TRANSNACIONALIDADE.

6 "Mas isso em nada altera a nova dependência do Estado Nacional às condições econômicas mundiais fundamentalmente diversas. A questão é saber se a constelação pós-nacional não precisa de outros atores políticos, capazes de maior ação". In: HABERMAS, 2001.
}

Revista do Direito [ISSN 1982-9957]. Santa Cruz do Sul, v. 2, n. 49, p. 29-45, maio/ago. 2016. https://online.unisc.br/seer/index.php/direito/index 
tratar do assunto afirmando que "Rio e Fronteira" é a nova imagem sugestiva para a nova constelação das ultrapassagens de fronteira. Na assembleia germanista de Frankfurt de 1846, tratava-se do estabelecimento das fronteiras nacionais que vigoram hoje em dia. Naquela época observávamos o início republicano. Desiludidos, observamos hoje seu fim num misto de desilusão e resignação. O olhar diagnóstico retrospectivo sobre o breve século XX tenta esclarecer a atmosfera atualmente disseminada de perplexidade iluminista. Habermas pondera que estamos dirigindo um olhar a um problema inquietante ao Século XXI e nos perguntamos se será possível manter a social democracia estatal com seu desenvolvimento para além da fronteira nacional (HABERMAS, 2001, p. 06). Algo como o que tratamos de "republicanização da globalização" (CRUZ; BODNAR, 2011 (a), 7583).

Assim como Harbemas, especialmente na obra A Constelação Pos-Nacional, começa-se a perceber a intensificação por propostas que consigam conciliar o "tempo" do mundo atual com o "tempo" do direito como o obejeto da ciência jurídica.

Os diversos estudos disponíveis e que tratam da transnacionalização do direito, como o Transconstitucionalismo (NEVES, 2009) ou o Transjudicialismo ${ }^{7}$ mostram que há o entrelaçamento de ordens jurídicas diversas, tanto estatais como transnacionais, internacionais e supranacionais, em torno dos mesmos problemas de natureza constitucional. Ou seja, problemas de direitos fundamentais e limitação de poder que são discutidos ao mesmo tempo por tribunais de ordens diversas.

O Direito Transnacional ou a transnacionalização dos instrumentos jurídicos capaz de criar um sistema jurídico ordenado e com princípios gerais estabelecidos começou a ser discutido na década de sessenta do Século XX.

Como já nos referimos em artigo anterior (CRUZ, OLIVIERO, 2012, p. 18-28), um dos primeiros pesquisadores modernos a utilizar esse termo foi Philip Jessup em sua obra denominada Transnational Law (JESSUP, 1965, p. 12), em 1965, na Universidade de Yale. Nessa obra, Jessup tenta tratar dos problemas aplicáveis à comunidade mundial inter-relacionada, que principia com o indivíduo e alcança a sociedade de estados. Por considerar que a comunidade mundial estava criando laços cada vez mais complexos, esse autor entendia que a expressão Direito Internacional

\footnotetext{
${ }^{7}$ É mais adequado pensar que as interações transjudiciais refletem pontos concretos de contato entre cortes, mas não necessariamente "diálogos" como formas bilaterais de comunicação. Mesmo porque não é comum que as cortes internacionais e supranacionais, que normalmente são citadas ao longo do sistema-mundo, retribuam a cortesia, citando precedentes de outras cortes estrangeiras. Acentue-se ainda que as interações transjudiciais decorram basicamente do esmaecimento das normas de direito internacional, especialmente aquelas que foram Interações transjudiciais e transjudicialismo. 0 objetivo primeiro da expansão dessas interações é ressaltar a liberdade ou voluntariedade, em certo sentido, que as cortes domésticas possuem para selecionar os precedentes não vinculantes que adotarão como fundamentos de suas decisões, da mesma forma como escolhem seus materiais doutrinários. Esse espaço de liberdade das cortes domésticas é que tende a ampliar-se com o contínuo enfraquecimento do papel das cortes internacionais e supranacionais. Interessa notar, portanto, que a ampliação das interações transjudiciais ao longo do sistema-mundo se desenvolve em sentido inversamente proporcional ao papel das cortes internacionais e supranacionais. (PEREIRA, 2012, p. 169-199).
} 
estaria superada e já não atendia às exigências conceituais da nova época que se desenhava ${ }^{8}$. Nesse sentido, consignou que utilizaria o termo Direito Transnacional para incluir todas as normas que regulassem atos ou fatos que transcendessem fronteiras nacionais (JESSUP, 1965, p. 12).

Jessup estava preocupado, na época, em não polemizar e evitava fazer afirmações que ensejassem discussões acadêmicas sobre a utilização do termo Direito Transnacional. Para evitar os longos debates, ele reduziu a noção dessa categoria como sendo apenas uma fonte mais abundante de normas com que se guiariam para além das fronteiras nacionais.

A proposta de Jessup gerou grande repercussão na academia norte-americana. Ainda hoje se encontram programas de estudos e publicações especializadas que empregam o termo "Transnational Law", no sentido abrangente por ele concebido, como, por exemplo, o Columbia Journal of Transnational Law. Merece também registro os diversas textos que identificam o Direito Transnacional à nova lex mercatoria, a regulação privada das transações internacionais por modelos contratuais e práticas comerciais consolidadas. (STRENGER, 1996)

A citação de Jessup serve como ponto de inflexão, pois o que ele estava captando, na época, era o início do fenômeno que se convencionou chamar de globalização e consentindo sobre o surgimento de um complexo emaranhado de relações à margem da capacidade regulatória e de intervenção do Estado Constitucional Moderno. Essa proposição, até mesmo pelo contexto histórico em que foi formulada, é insuficiente para a discussão que desde a alguns anos se pretende empreender sobre o Direito Transnacional. Também como já escrevemos anteriormente, ao contrário do que pensava Jessup, nas primeiras décadas do Século XXI será fundamental o debate sobre o tema.

Atualmente, o Estado não consegue mais dar respostas consistentes à Sociedade diante da complexidade das demandas transnacionais que se avolumam continuamente. Os problemas sociais aumentam em proporções preocupantes.

Tudo leva a crer que o principal fator dessas crises cíclicas esteja localizado exatamente no caráter obsoleto do próprio Estado Constitucional Moderno (CRUZ, OLIVIERO, 2014, p. 148-165).

Há também uma clara crise conceitual sobre o sentido clássico da categoria Nação, na linha adotada por Ernest Gelner (1997, p. 62), em sua obra Naciones y Nacionalismos. É uma crise da denominada Nação Jurídica, formada a partir da Nação Cultural e da Nação Política, como tratada por Gelner em sua obra.

O debate sobre o Direito Transnacional justifica-se, então, principalmente no fato de que o Direito Nacional e o Direito Internacional - mesmo considerando a criação de novas estruturas e organizações interestatais - não geraram mecanismos eficazes de governança, regulação, intervenção e coerção para as demandas transnacionais. Também o Direito Comunitário, que regula uma das manifestações da nova ordem mundial, caracterizada por novas relações e novas manifestações de atores e instituições, não apresenta bases teóricas suficientes para a caracterização de um ou mais espaços públicos transnacionais.

\footnotetext{
${ }^{8}$ Para Jessup o Direito Transnacional inclui todo o direito que regula ações ou eventos que transcendem fronteiras nacionais. Tanto o Direito Internacional Público quanto o Privado estão incluídos, assim como estão outras regras, que não se encaixam perfeitamente nessas categorias usuais.
}

Revista do Direito [ISSN 1982-9957]. Santa Cruz do Sul, v. 2, n. 49, p. 29-45, maio/ago. 2016. https://online.unisc.br/seer/index.php/direito/index 
Com base nos elementos de discussão política sobre a necessidade de se ter o Direito Transnacional como instrumento de limitação dos poderes transnacionais, é possível se especular que serão intensificados os processos de abdicação das competências soberanas dos estados constitucionais modernos.

A constatação de que o mundo se caracteriza por uma multiplicidade de ordens normativas e poderes não sujeitos a qualquer direito e que o Estado é só uma forma de ordenamento entre outras, ainda que muito importante, é o ponto de partida para se poder entender porque emergiu a necessidade de âmbitos de governança e como estaria estruturada.

As estruturas transnacionais poderão operar dentro de um amplo espectro de Estados articulados juridicamente, e a maioria dos conflitos sociais que enfrentam é processada através da adesão ao direito estatal ou através da compatibilidade com ele (BAUMAN, 2001, p. 132). Mesmo assim, o direito estatal se caracteriza por profundas diferenças de concepções, filosofias regulatórias e tradições jurídicas. Para as organizações internacionais públicas e privadas o problema de garantir que as ações legais possam se plasmar de forma precisa nos ordenamentos jurídicos nacionais continua sendo um grande desafio.

Fenômenos como os da exclusão social e da insustentabilidade do desenvolvimento põem em xeque ações e o próprio papel do Estado na sua obrigação histórica de zelar pela segurança humana, pela educação e pelos direitos da cidadania (REAL FERRER, DANTAS, BONISSONI, 2014, p. 1340-1363). Nesta reflexão, ações como essas transpassam caminhos atípicos: somatório dialógico entre valores como a ética, a justiça e a questão ambiental, amarrando possibilidades para um presente sustentável. Isto significa navegar em busca de riquezas explicativas novas, não apenas necessárias à exegese da fenomenologia dos porquês da desordem social e da desordem ecológica, mas também para saber o como as coisas acontecem dentro e fora da globalização (PROCÓPIO FILHO, 2011, p. 67).

Nas nações da periferia mundial, amarradas pelas burocracias que deixam de incrementar as conhecidas alternativas de sustentabilidade, o risco é ainda maior. É paradoxal que se imponham tantos entraves e dificuldades para a implantação de sistemas de geração de energias alternativas, como a eólica e a solar, por exemplo, como tem ocorrido sistematicamente no Brasil, em que situações como estas chegam a ser levadas ao Poder Judiciário. No caso de alguns países, os privilégios de suas elites, a generalizada corrupção e a perversa distribuição da renda sob o patrocínio do próprio Estado, proporcionalmente tinge de sangue, mais que noutros países, a natureza e o tecido social da nação. Daí a degradação ambiental associada à baixíssima qualidade de vida do povo, que normalmente andam juntas. Daí também a violência. Tudo isso significa ameaça à democracia e à paz, porque fragiliza a unidade nacional (CRUZ, 2007, p. 17-40).

Não faz sentido o ser humano insistir que pode simplesmente continuar sua evolução enclausurada nos dogmas do Direito Moderno. Todos sabem que a modernidade, apesar de ter representado significativo avanço para a humanidade, acabou sendo todo um sistema teórico de justificação de desigualdades.

Revista do Direito [ISSN 1982-9957]. Santa Cruz do Sul, v. 2, n. 49, p. 29-45, maio/ago. 2016. https://online.unisc.br/seer/index.php/direito/index 
As desigualdades em seu sentido mais amplo: social, econômica, cultural e tecnológica, constituem um dos fatores de maior agressão ao ambiente ${ }^{9}$. Estima-se que a miséria e a pobreza respondam por um terço de toda degradação ambiental no planeta.

Neste contexto de crise multidimensional, surge um cenário extremamente receptivo para a emergência de novas instituições políticas e jurídicas que sejam capazes de agregar e articular atitudes solidárias e cooperativas. Com a capacidade de envolver as pessoas, instituições e estados na luta pela proteção de bens e valores imprescindíveis para assegurar a vida plena e duradoura no planeta $^{10}$.

É importante refletir seriamente sobre o câmbio valorativo produzido pelo ambiente criado com o fim da bipolarização ideológica propiciado pelo fim do mundo soviético, pela globalização e, principalmente, pelos sintomas evidentes de crise ecológica presentes no atual cenário mundial. Pela primeira vez o homem deu-se conta que pode, efetivamente, por termo à vida na terra. As mudanças climáticas não são mais apenas uma ideia de ambientalistas radicais, mas uma realidade a que não podemos nos furtar em crer (NOLON; SALKIN, 2011).

A evolução da sociedade e o crescimento exponencial da complexidade, em todas as dimensões, conduzem à inexorável certeza de que não é mais suficiente assegurar amplamente a liberdade, a igualdade material, dentre outros direitos de tipo apropriativo, próprios do capitalismo. Não se o mundo estiver à beira do colapso pelo esgotamento dos recursos naturais. (REAL FERRER, 2012 (b), p. 65-82)

O monopólio do Estado Constitucional Moderno, como única fonte legítima de lealdade política para seus cidadãos, começa a ceder seu lugar a um conjunto de identidades políticas mais pluralistas e múltiplas. As pessoas começam a se definir como membros de uma comunidade local, de uma nação ou uma federação multinacional, de uma região ou subcontinente, e como cidadãos do mundo. Esta evolução será o motor propulsor para a construção dos novos parâmetros de justiça (CRUZ; BODNAR, 2011(b), p. 269-286). Os seus impulsos universalistas e seus princípios orientarão seus seguidores para além de qualquer compromisso com um só nível de proposição jurídica e para além do Estado Constitucional Moderno na direção da construção de princípios de uma necessária teoria para a justiça transnacional numa globalização democrática.

A compreensão da sustentabilidade, enquanto novo paradigma do direito deve resultar do aporte cognitivo fornecido pela sociologia, economia ${ }^{11}$ e também pela filosofia. Resta à Ciência

\footnotetext{
9 "Mais importante, eu acredito que a preocupação e a ênfase no meio ambiente não é mais somente uma questão social, negocial ou ética. É uma questão de civilização" (HAWKEN, 2010, p. xxi).

${ }^{10}$ Não é à toa que boa parte dos países hoje adotem a proteção ambiental em suas Constituições, a exemplo do que fez o Brasil. Sobre o tema, v. (MAY; DALY, 2014). Mesmo em países com sistemas constitucionais mais rígidos, como os EUA, p. ex., têm tradado a questão ambiental no plano de outras cláusulas constitucionais, como se verifica em (MAY, 2011). Não é à toa que a Suprema Corte daquele país venha julgando tantos casos ambientais, já não é de hoje, mas desde pelo menos a década de 70, época do célebre julgamento do caso TVA vs. Hill (MURCHINSON, 2007. DOREMUS, 2005, p. 109-140).

${ }^{11}$ Cada vez mais nos convencemos que a economia tem um papel relevante para a conservação da natureza. Em um mundo em que os mecanismos de comando e controle não se revelaram suficientes para combater a degradação ambiental de que o planeta foi vítima, os incentivos econômicos à preservação surgem como uma alternativa viável e de previsível eficácia para combater o fenômeno. Sobre o tema, v., dentre outros: NUSDEO, 2012. MONTERO, 2014.
}

Revista do Direito [ISSN 1982-9957]. Santa Cruz do Sul, v. 2, n. 49, p. 29-45, maio/ago. 2016. https://online.unisc.br/seer/index.php/direito/index 
Jurídica, a importante função de se adequar a esta pauta axiológica comum humanitária, captar as realidades sociais, os seus desvios e riscos e promover estratégias objetivando mitigá-los e controlálos para a realização plena do bem comum (LARRUGA et al, 2013).

Pode-se dizer que a sustentabilidade não é mais do que a materialização do instinto de sobrevivência social. Segundo Gabriel Real (2012(a), p. 310-316), para alcançar uma sociedade sustentável supõe-se que:

a) a sociedade que consideramos seja planetária, nosso destino é comum e não cabe a sustentabilidade parcial de uma comunidade nacional ou regional à margem do que pode ocorrer no resto do planeta. Construir uma comunidade global de cidadãos ativos é indispensável para o progresso da sustentabilidade. Esta exigência exige, entre outras coisas, superar a visão "ocidental" e, anglo-saxônica que temos o mundo;

b) alcançarmos um pacto com a terra de modo que nos comprometemos com a possibilidade de manter os ecossistemas essenciais que fazem possíveis a nossa subsistência como espécie em uma condição ambiental aceitável. É imprescindível reduzir drasticamente nossas demandas de consumo de capital natural para alcançar níveis razoáveis de reposição;

c) sejamos capazes de alimentar e, mas ainda, oferecer uma vida digna ao conjunto de habitantes do planeta, acabando com injustificáveis desigualdades. Para isso será preciso reconsiderar e reformular os modos de produção e distribuição de riquezas. A fome e a pobreza não são sustentáveis;

d) Recompormos a arquitetura social de modo que acabemos com o modelo opressor que esta baseando o conforto e o progresso de apenas algumas "castas" (classes) sociais em exclusão sistemática de legiões de indivíduos desfavorecidos, órfãos de qualquer oportunidade. Alcançar um mínimo limiar de justiça social é uma condição inevitável para caminhar para a sustentabilidade ${ }^{12}$;

e) construirmos novos modelos de governança que assegurem a prevalência dos interesses gerais sobre os individuais sejam esses de indivíduos, corporações ou Estado. Trata-se de politizar a globalização, pondo-a a serviço das pessoas e estendendo mecanismo de governo baseados em novas formas de democracia com arquitetura assimétrica e baseada na responsabilidade dos cidadãos;

d) Será preciso colocar a ciência e a técnica a serviço de objetivos comuns. Não só os novos conhecimentos devem ajudar a corrigir erros passados, ou apontar soluções eficazes aos problemas que surgem em uma civilização energético-dependente, mas a tecnologia deverá inevitavelmente determinar quais serão os modelos sociais que iremos nos desenvolver.

Esse conjunto de proposições tornam os desafios do nosso tempo ainda maiores. Sobretudo, porque a sustentabilidade emerge como grande potencial axiológico pós-moderno, e que precisa coabitar com os paradigmas da liberdade (indutor do direito moderno), fraternidade e igualdade (indutores das relações sociais), bem como, fomentar o exercício da cidadania como um sentir e agir solidário na dimensão transnacional.

\footnotetext{
12 “Você não pode encarar questões de justiça social sem justiça ambiental. Você não pode imaginar um mundo próspero sem um clima estável. Você não pode imaginar um sistema de agricultura que funcione sem encarar a diversidade biológica ou hidrológica. E você não pode imaginar uma educação relevante para uma criança sem que não esteja baseada na compreensão do meio ambiente" (HAWKEN, 2010).
}

Revista do Direito [ISSN 1982-9957]. Santa Cruz do Sul, v. 2, n. 49, p. 29-45, maio/ago. 2016. https://online.unisc.br/seer/index.php/direito/index 
Portanto, para que a sustentabilidade possa consolidar-se como paradigma dominante, ela deverá ser construída a partir de múltiplas dimensões, que incluem as variáveis ecológicas, sociais, econômicas e tecnológicas. Sem esquecer-se da jurídica, num contexto de comunicação sistêmica e comunhão dos sistemas que possibilitem o agir democrático, portanto, cidadão e solidário transnacional.

A Sustentabilidade como um imperativo ético tridimensional deve ser implementada em solidariedade sincrônica com a geração atual, diacrônica com as futuras gerações, e em sintonia com natureza, ou seja, em benefício de toda a comunidade de vida e dos elementos abióticos que lhe dão sustentação ${ }^{13}$.

Como já escrito anteriormente, há um claro sentimento de carência, nesse começo de Século XXI, de um "passo adiante" civilizatório. As últimas gerações humanas são devedoras de um efetivo novo avanço na questão do que se pode chamar de um mundo solidário e humanizado. (CRUZ; BODNAR, 2009, p. 09) A modernidade caracterizou um significativo avanço, apesar de um avanço baseado no individualismo. O mundo atual é por demasiado complexo para seus obsoletos paradigmas teóricos.

Deve-se compreender, não custa repetir e já escrevemos em artigos anteriores, que esta nova era não deve ser combatida - seria trabalho inútil - e sim ser objeto de novas teorizações, que possam conduzir a humanidade ao seu episódio seguinte, sempre com a perspectiva de uma evolução positiva.

A complexa crise global atual, que se manifesta em todos os setores da vida humana e da vida de um modo Geral e já começa a envolver por completo a civilização. Ela nos obriga a formular a pergunta se alcançamos o ponto denominado em inglês de over sea, aquele ponto que não nos permite retroceder na história da espécie humana pelo menos tal como foi definida desde o aparecimento das grandes culturas, que marcaram o começo da "consciência histórica" (HABERMAS, 2006, p. 98). Nossa busca por um sentido de pertencimento universal nos lançou para realidades sociais e econômicas cada vez mais complexas, cada uma delas foi ocupando e transformando o globo terrestre que todos habitamos. Colonizamos até o último metro quadrado do planeta e assentamos as bases de uma civilização efetivamente global que permite a conexão de toda a espécie humana, mas às expensas de um passivo ambiental real, que ameaça a humanidade com o fim da vida no planeta (RIFKIN, 2010).

Nos momentos atuais de pura perplexidade - com um misto de apoplexia - quando a sociedade humana perde o controle de seu próprio sentido dos conceitos de intimidade e universalidade, quando os temores da humanidade se manifestam em forma de opressão e de uma violência incontrolável. Multiplicam-se as ações terroristas em todo mundo. Como escreve Rifkin,

\footnotetext{
${ }^{13}$ Um mecanismo muito interessante para implementar este desafio é a criação de parques nacionais, nos moldes como feito pelo país idealizador da medida, os Estados Unidos da América. "Apesar de normalmente proclamado como 'a melhor ideia da America', a ideia do parque nacional é na verdade não apenas uma simples ideia, mas em vez disso um amálgama de ideias que evoluíram ao longo do tempo. As ideias ou conceitos centrais que definem um parque nacional fazem isso em inúmeros termos bem distintos como uma área selvagem, uma destinação turística, um playground recreativo, uma commodity comercial, uma pátria ancestral, um laboratório natural, uma reserva de vida selvagem, e, mais recentemente, um pilar ecológico vital" (KEITER, 2013).
}

Revista do Direito [ISSN 1982-9957]. Santa Cruz do Sul, v. 2, n. 49, p. 29-45, maio/ago. 2016. https://online.unisc.br/seer/index.php/direito/index 
todas as civilizações tiveram seus alertas sobre seus holocaustos. Parece que não está diferente com a civilização moderna.

É em função disso que Rifkin trabalha a evolução humana no atual contexto de transnacionalização como possível a partir da predisposição empática inscrita na nossa essência humana. Nosso organismo não é um mecanismo à prova das violências que nós mesmos cometemos contra nós, mas nossa capacidade empática pode representar a oportunidade para unir a espécie humana em torno de elementos de oportunidade que devem ser exercitados de maneira continuada (RIFKIN, 2010). Lamentavelmente, o impulso empático tende a ser colocado numa posição secundária quando as forças sociais se enfrentam por questões pouco ou nada republicanas que ameaçam desintegrá-la (CRUZ, 2008, p. 1-10).

Podemos estar nos aproximando de um daqueles momentos evolutivos que determinam o surgimento de uma nova idade ou era. Alguns autores tratam esse novo tempo como um terceiro momento do mundo industrializado, com uma fundamental mudança no meio de produção que pode ser chamado, provisoriamente, é claro, de capitalismo distributivo. Rafael Padilha dos Santos, em sua tese de doutorado defendida em dupla titulação (não apenas cotutela como muitos fazem) entre a UNIVALI e a Universidade de Perugia, em 2015, já trabalhou algumas dessas teorias sobre o capitalismo distributivo (SANTOS, 2015).

Essa nova era do capitalismo distributivo, sobejamente tratado na obra citada de Jeremy Rifkin, pode nos ajudar a propor um novo arcabouço teórico suficiente para permitir que o Direito e a Ciência Jurídica enfrentem os desafios da globalização com um mínimo de possibilidades de êxito. Apontando uma "continentalização" de baixo para cima. Isso implica que os novos critérios de produção sustentáveis estejam distribuídos de maneira mais ou menos igualitária em todo o mundo (RIFKIN, 2010). É fundamental que todas as regiões do planeta possam desfrutar, pelo menos parcialmente, dos meios necessários para que sejam relativamente autossuficientes de meios para a manutenção de um estilo de vida sustentável, ao mesmo tempo em que possam conectar-se com diversas regiões em países e continentes, através de redes inteligentes.

Sabe-se perfeitamente das assimetrias existentes entre as diversas regiões do nosso planeta e entre os países que as formam (CRUZ; REAL FERRER, 2010, p. 12-24). Isso mostra a necessidade de coabitação entre o paradigma moderno e o pós-moderno do Direito, entre a busca por âmbitos cada vez mais amplos de liberdade e a limitação desta mesma liberdade em função de se promover a sustentabilidade (CRUZ; REAL FERRER, 2011, p. 1-23). É o que já referimos anteriormente como "republicanização da globalização", com uma efetiva busca pela distribuição da riqueza e reequilíbrio ambiental em escala global. O grande desafio do ser humano será provar que conseguirá evoluir do individualismo liberal, passando pelas experiências de igualdade relativa dos estados de bem estar até alcançar a sustentabilidade. Provar que não é um elemento estranho e inadaptável ao planeta Terra, mas que pode não só conviver em harmonia como melhorar as condições gerais de vida. $\mathrm{A}$ percepção geral dos governos mundiais hoje em dia, inclusive dos países mais desenvolvidos parece estar em consonância com este entendimento. Basta ver o teor do acordo de Paris para se chegar a esta conclusão.

Revista do Direito [ISSN 1982-9957]. Santa Cruz do Sul, v. 2, n. 49, p. 29-45, maio/ago. 2016. https://online.unisc.br/seer/index.php/direito/index 
A proteção do meio ambiente é uma pauta axiológica reconhecida e valorizada em escala global. Hoje não é mais um desafio exclusivo para a Ciência Jurídica a criação e a sistematização de normas de proteção ao ambiente. O caminho mais complexo e relevante a ser trilhado é o conjunto intersistêmico de relações que o ambiente gera com outros bens e valores, principalmente nas perspectivas sociais, econômicas, culturais e tecnológicas.

Atualmente não é mais suficiente somente o desenvolvimento de teorias jurídicas complexas e sofisticadas em relação a temas e institutos setoriais do fenômeno da convivência humana (CRUZ; BODNAR, 2011(a), p. 75-83). É de duvidosa utilidade, por exemplo, compreender tecnicamente o significado do direito de propriedade se este valor não é entendido e relacionado com as suas múltiplas manifestações e inúmeras relações que desencadeia, das rotas de colisão, parcial concordância e plena harmonização com outros institutos jurídicos ${ }^{14}$. Inclusive nas suas repercussões econômicas, culturais e tecnológicas.

Desta forma, com os cenários transnacionais atuais surge a necessidade da emergência e da consolidação de um novo paradigma do Direito que deve ser mais dúctil e operacionalmente adequado para a produção dialética e democrática de um repertório de argumentos mais densos e legítimos no atual contexto de complexidade.

A sustentabilidade emerge, naturalmente, como grande potencial axiológico para ser aplicada e reconhecida na centralidade desta nova ordem jurídica altamente complexa, plural e transnacionalizada (CRUZ; BODNAR, 2011 (a), p. 75-83).

A colaboração e a solidariedade transnacionais também são as palavras de ordem para a sustentabilidade global. A intensificação do fenômeno da globalização apresenta desafios importantes aos Estados. Exige uma readequação qualitativa e estratégica do Direito, pois este enquanto instrumento de controle social estatal, emanado de um ente soberanamente isolado no planeta, já não produz mais respostas eficazes para assegurar um futuro com sustentabilidade progressiva para toda a comunidade de vida e em escala global ${ }^{15}$.

Necessita-se da construção e consolidação de uma nova concepção de sustentabilidade global, como paradigma de aproximação entre os povos e culturas, e na participação do cidadão de

\footnotetext{
${ }^{14}$ Sobre o tema, v. DANTAS, 2015, p. 187-211.

${ }^{15} \mathrm{Um}$ bom exemplo deste novo fenômeno emana da decisão da Suprema Corte Americana no caso conhecido como Massachussets vs. EPA, em que o Tribunal admitiu que a Agência de Proteção Ambiental do país pode estabelecer parâmetros de emissão de gases de efeito estufa que contribuem para o aquecimento global (PERCIVAL, 2011, p. 1.105-1.122. A decisão, tomada por maioria apertada de votos (5x4, Relator Justice J. Stevens, acompanhado por Kennedy, Souter, Ginsburg e Breyer e, vencidos, Roberts, Scalia, Thomas e Alito), por sua importância histórica e seu conteúdo, é referida em praticamente todos os foros de Direito Ambiental no país. Na doutrina, dentre outros, v. FARBER; FREEMAN; CARLSON, 2010. p. 403-412. WEINBERG, Philip. REILLY, Kevin A. Understanding Environmental Law, p. 6, 88 e 427). Também sobre o tema, com decisão da Corte no mesmo sentido, v. American Electric Power Co v. Connecticut, Relatora Justice Ginsburg, in PERCIVAL; SCHROEDER, 2011 p. 1.123-1.128). No momento em que se escreve este artigo, contudo, é veiculada notícia pelo Valor Econômico que a Corte, também por maioria apertada de votos $(5 X 4)$ suspendeu a aplicação da ordem regulatória que impõe limites à emissão de gases poluentes para o setor de geração de eletricidade, em ação movida por 29 Estados e dezenas de indústrias (http://www.valor.com.br/internacional/4429318/suprema-corte-bloqueia-plano-de-obama-para-conteremissoes-de-gases; acesso em 12/02/16).
}

Revista do Direito [ISSN 1982-9957]. Santa Cruz do Sul, v. 2, n. 49, p. 29-45, maio/ago. 2016. https://online.unisc.br/seer/index.php/direito/index 
forma consciente e reflexiva na gestão política, econômica e social (CRUZ; OLIVIERO, 2012, p. 1828).

A sustentabilidade deve ser construída a partir de múltiplas dimensões que incluam, além da jurídica, as variáveis ecológica, social, econômica e tecnológica, tendo como base forte o meio ambiente. Para o Direito como objeto da Ciência Jurídica, todas estas perspectivas apresentam identificação com a base de valores fundamentais, aí incluídos o meio ambiente, desenvolvimento sustentável, direitos prestacionais sociais, dentre outros, cada qual com as suas peculiaridades e riscos. Pela importância e centralidade na ordem política atual, é possível afirmar assim que a sustentabilidade pode ser compreendida como impulsionadora do processo de consolidação de uma nova base meta axiológica ao Direito.

A denominada "continentalização", para usar o termo proposto por Rifkin sugere a necessidade de um decisivo movimento distributivo da riqueza. Indica que a globalização da base da sociedade e que já atinge os lugares mais remotos do planeta, provavelmente nos permitirá completar a tarefa de analisar uma sociedade humana cada vez mais conectada. Essa condição inaugura a possibilidade de se ampliar o sentimento de pertencimento a uma sociedade global com alto grau de empatia e capaz de atuar em situações as mais diversas e nos temas que conformam a vida no planeta (RIFKIN, 2010).

Principalmente na formação da "consciência para a sustentabilidade".

Essa condição empática, própria desse mundo novo, deverá nos ajudar a refletir sobre o quão irônico é o fato de que a mudança climática nos obriga, mais do que nunca, a reconhecer nossa humanidade compartilhada e nossa condição comum de maneira essencial e não só superficial. Vivemos todos nesse planeta, ou seja, não existe nenhum lugar para onde possamos escapar ou nos esconder. A fatura entrópica que a espécie humana gerou afeta todo o planeta e ameaça com a possibilidade de nossa extinção.

\section{CONSIDERAÇÕES FINAIS}

Os fatos históricos vividos pelo mundo, principalmente no século passado, demonstram cada vez mais o aumento da sensação de esgotamento das bases modernas que levaram a civilização ocidental a diversos paradoxos impressionantes.

Contudo, foram nesses últimos 50 anos que houve as maiores mudanças, as pessoas, as comunicações, a cultura e a geopolítica mudaram. A Primavera Árabe aconteceu e os problemas dos países árabes pioraram. Todas as áreas do conhecimento foram e estão sendo atingidas em cheio por isso que podemos chamar de fim da segunda modernidade. Ou, talvez seja mais adequado, da saturação seletiva de alguns corolários modernos.

A realidade é que a humanidade encontra-se num momento decisivo da história, tendo em vista o fato de que o caminho para uma consciência global compartilhada está sendo trilhado de maneira muito rápida e acompanhado por intervenções humanas na natureza cada vez mais intensas. É o que Rifkin chama de "colapso entrópico".

Revista do Direito [ISSN 1982-9957]. Santa Cruz do Sul, v. 2, n. 49, p. 29-45, maio/ago. 2016. https://online.unisc.br/seer/index.php/direito/index 
As pessoas que cuidam do Direito, ou da Ciência Jurídica, não podem e não devem desconsiderar essa realidade. A mudança progressiva do paradigma moderno para o novo paradigma faz com que cada vez mais pesquisadores de todas as áreas do conhecimento convirjam para a sustentabilidade a uma velocidade espantosa.

O que se faz agora é também acelerar o debate sobre a formação da base conceitual e de caracterização para a categoria Direito Transnacional, que atualmente ainda se apresenta de maneira difusa e com algumas categorias construtivas, como o é o Transconstitucionalismo e o Transjudicialismo.

É imperioso reconhecer o surgimento de todos os fenômenos que acabam por alterar a compreensão tradicional e corrente das categorias modernas do Direito, tais alterações permitem projetar mudanças que, embora careçam de sustentação empírica, deflui de um consenso mínimo axiológico gerador de novos modelos.

O debate sobre o Direito Transnacional justifica-se, então, principalmente no fato de que o Direito Nacional e o Direito Internacional não geraram mecanismos eficazes de governança, regulação, intervenção e coerção para as demandas transnacionais. Também o Direito Comunitário, que regula uma das manifestações da nova ordem mundial, caracterizada por novas relações e novas manifestações de atores e instituições, não apresenta bases teóricas suficientes para a caracterização de um ou mais espaços públicos transnacionais.

A constatação de que o mundo se caracteriza por uma multiplicidade de ordens normativas e poderes não sujeitos a qualquer direito e que o Estado é só uma forma de ordenamento entre outras, ainda que muito importante, é o ponto de partida para se poder entender porque emergiu a necessidade de âmbitos de governança e como estaria estruturada.

Nesse diapasão que se mostra imperioso compreender a sustentabilidade como novo paradigma do direito, resultante do aporte cognitivo fornecido pela sociologia, economia e filosofia. Restando à Ciência Jurídica, a importante função de se adequar a esta pauta axiológica comum.

Esse conjunto de proposições tornam os desafios do nosso tempo ainda maiores. Sobretudo, porque a sustentabilidade emerge como grande potencial axiológico pós-moderno, e que precisa coabitar com os paradigmas da liberdade (indutor do direito moderno), fraternidade e igualdade (indutores das relações sociais), bem como, fomentar o exercício da cidadania como um sentir e agir solidário na dimensão transnacional.

Por tudo isso que se faz necessária a construção e consolidação de uma nova concepção de sustentabilidade global, como paradigma de aproximação entre os povos e culturas, e na participação do cidadão de forma consciente e reflexiva na gestão política, econômica e social.

\section{REFERÊNCIAS}

BAUMAN, Zigmund. 44 Cartas Do Mundo Líquido Moderno. Tradução: Vera Pereira, Rior de Janeiro: Zahar Editora, 2001.

CRUZ, Paulo Márcio. Soberania e superação do Estado Constitucional Moderno. Revista Juridicas Universidade de Caldas. Colombia, v. 4, p. 17-40, 2007. 
CRUZ, Paulo Márcio. Sobre el principio republicano. Revisa de Derecho. E-LeX Revista. Barcelona, Espanha, v. 63, p. 1-10, 2008.

CRUZ, Paulo Márcio; BODNAR, Z. A atuação do Poder Judiciário na implementação das políticas públicas ambientais. Revista Brasileira de Estudos Constitucionais, São Paulo, v. 5, p. 269-286, 2011 (b).

CRUZ, Paulo Márcio; BODNAR, Z. O novo paradigma de Direito na pós-modernidade. RECHTD/UNISINOS. Revista de Estudos Constitucionais, Hermenêutica e Teoria do Direito, Porto Alegre, v. 3, p. 75-83, 2011 (a).

CRUZ, Paulo Márcio; BODNAR, Z. La Transnacionalidad y la Emergencia del Estado y del Derecho Transnacionales. Revista V-Lex, Barcelona, v. 4, p 09 -

CRUZ, Paulo Márcio; REAL FERRER, G. A crise financeira mundial, o estado e a democracia econômica. Revista da Faculdade de Direito da UERJ, Rio de Janeiro, v. 1, p. 1-23, 2011.

CRUZ, Paulo Márcio; REAL FERRER, G. Los nuevos escenarios transnacionales y la democracia asimétrica. E-Lex Revista, Barcelona - Espanha, v. 5, p. 12-24, 2010.

CRUZ, Paulo Márcio; OLIVIERO, Maurizio. Reflexões sobre a crise financeira internacional e o Estado de Bem-Estar. Revista Quaestio Juris, Rio de janeiro, v. 7, n. 1, p. 148-165, 2014.

CRUZ, Paulo Márcio; OLIVIERO, Maurizio. Reflexões sobre o direito transnacional. Revista Novos Estudos Jurídicos, Itajaí, v. 17, n. 1 - Edição Especial Rio +20, p. 18-28, 2012.

DANTAS, Marcelo Buzaglo. Direito Ambiental de conflitos: o direito ao meio ambiente equilibrado e os casos de colisão com outros direitos fundamentais. Rio de Janeiro: Lumen Juris, 2015, p. 187-211.

DIAMOND, Jared. Colapso: como as sociedades escolhem o fracasso ou o sucesso. 7. ed. Rio de Janeiro: Record, 2010.

DOREMUS, Holly. The story of TVA v. Hill: a narrows cape for a broad new law. In: LAZARUS, Richard J. HOUCK, OLIVER A. (Editors). Environmental Law stories. New York/NY: Foundation Press, 2005, p. 109-140.

FARBER, Daniel. FREEMAN, Jody. CARLSON, Ann. Cases and materials on Environmental Law. Eighth Edition. St. Paul: West, 2010. p. 403-412. WEINBERG, Philip.

GELNER, Ernest. Naciones y nacionalismos. Madrid: Alianza, 1997.

HABERMAS, Jurgen. A constelação pós-nacional. Trad. Márcio Seligmann-Silva. São Paulo: LITTERA MUNDI, 2001.

HABERMAS, Jürgen. O Ocidente Dividido. Tradução de Luciana Villas-Bôas. Rio de Janeiro: Tempo Brasileiro, 2006.

HAWKEN, Paul. The ecology of commerce: a declaration of sustainability. New York: Harpen Business, 2010.

HOUCK, Oliver. Taking Back Eden: Eight Environmental Cases that Changed the World. Washington: Island Press, 2010.

JESSUP, Philip C. Direito transnacional. Tradução de Carlos Ramires Pinheiro da Silva. São Paulo: Fundo de Cultura, 1965.

KEITER, Robert B. To Conserve Unimpaired: The evolution of the National Park idea. Washington: Island Press, 2013. 
KUHN, T. S. A estrutura das revoluções científicas. Tradução de Beatriz Vianna Boeira e Nelson Boeira. 5. ed. São Paulo: Perspectiva. 2000.

LARRUGA et al. (Dirs.). Libre mercado y protección ambiental: Intervención y orientación ambiental de las atividades económicas. Madrid: Instituto Nacional de Administración Pública, 2013.

MAY, James R. (Editor). Principles of Constitutional Environmental Law. Chicago: American Bar Association Publishing, 2011.

MAY, James R.; DALY, Erin. Global environmental constitutionalism. Nova York: Cambridge University Press, 2014.

MONTERO, Carlos Eduardo Peralta. Reflexões sobre a introdução variável ambiental no sistema tributário. São Paulo: Saraiva, 2014.

MURCHINSON, Kenneth M. The snail darter case: TVA versus the Endangered Species Act. Lawrence: University Press of Kansas, 2007.

NEVES, Marcelo. Transconstitucionalismo. Rio de Janeiro: Martins Fontes, 2009.

NOLON, John R. SALKIN, Patricia E. Climate Change and Sustainable Development Law in a nutshell. St. Paul: West Publishing, 2011.

NUSDEO, Ana Maria de Oliveira. Pagamento por Serviços Ambientais. São Paulo: Atlas, 2012.

PERCIVAL, Robert H. SCHROEDER, Christopher H. Environmental Law: Statuary and case supplement 2011-2012. New York: Wolters Kluwer Law\& Business, 2011 p. 1.105-1.122.

PROCÓPIO FILHO, Argemiro. Subdesenvolvimento Sustentável. 5. ed. Revista e Atualizada. Curitiba: Juruá Editora, 2011. v. 1. 368p.

REAL FERRER, Gabriel; DANTAS, Marcelo Buzaglo; BONISSONI, Natammy Luana. O processo de Internacionalização da Proteção Ambiental e dos Direitos Humanos. Novos Estudos Jurídicos (Online), Itajaí, v. 19, p. 1340-1363, 2014.

REAL FERRER, Gabriel Real. Calidad de vida, medio ambiente, sostenibilidad y ciudadanía. Construímos juntos el futuro? Novos Estudos Jurídicos (Online), Itajaí, v. 17, n. 3, p. 310-316, 2012 (a).

REAL FERRER, Gabriel. Sostenibilidad, transnacionalidad e transformaciones del Derecho. Revista de Derecho Ambiental - Doctrina, Jurisprudencia, Legislación práctica. Buenos Aires, p. 65-82, octubre/diciembre 2012 (b).

RIFKIN, Jeremy. La civilización empática: la carrera hacia una conciencia global en un mundo en crisis. Madrid: Paidós, 2010.

PEREIRA, Ruitemberg Nunes. Interações transjudiciais e transjudicialismo: sobre a linguagem irônica no direito internacional. Revista de Direito Internacional, Brasília, v. 9, n. 4, p. 169-199, 2012.

SANTOS, Rafael Padilha dos. O Princípio da Dignidade da Pessoa Humana como regulador da Economia no Espaço Transnacional: uma proposta de economia humanista. Tese de Doutorado (Doutorado em Ciência Jurídica). Programa de Pós-Graduação Stricto Sensu em Ciência Jurídica, Univali, 2015. 2 Disponível em: <http://www.univali.br/Lists/TrabalhosDoutorado/Attachments/69/Tese\%20-

\%20RAFAEL\%20PADILHA\%20-\%202015\%20-\%20Dupla.pdf>. Acesso em: 05 de abril de 2016.

SOUZA, E. B.; PINHEIRO, V. S. Tomás de Aquino e a razão natural dos direitos humanos: pessoa e bem comum. Revista do Direito, Santa Cruz do Sul. v. 1, n. 48, p. 70-91, jan. - abri. 2016.Disponivel em:< https://online.unisc.br/seer/index.php/direito/article/view/6593>. Acesso em: 12 mar. 2016.

STRENGER, Irineu. O direito do comércio internacional e Lex Mercatoria. São Paulo: LTR, 1996. 
ZANON, Orlando. Teoria Complexa do Direito. São Paulo: Editora Prismas, 2015.

\section{COMO CITAR ESSE DOCUMENTO}

DANTAS, Marcelo Buzaglo; OLIVIERO, Maurizio; CRUZ, Paulo Marcio. Direito, transnacionalidade e sustentabilidade empática. Revista do Direito, Santa Cruz do Sul, v. 2, n. 49, maio 2016. ISSN 19829957. Disponível em: <https://online.unisc.br/seer/index.php/direito/article/view/7911>. Acesso em: doi:http://dx.doi.org/10.17058/rdunisc.v2i49.7911. 